\title{
The influence of topography and fire in controlling landscape composition and structure in Sierra de Gredos (Central Spain)
}

\author{
Olga Viedma
}

Received: 8 October 2007 / Accepted: 19 April 2008/Published online: 14 May 2008

(C) Springer Science+Business Media B.V. 2008

\begin{abstract}
Mediterranean landscapes are dynamic systems that undergo temporal changes in composition and structure in response to disturbances, such as fire. Neither landscape patterns nor driving factors that affect them are evenly distributed in space. Accordingly, disturbances and biophysical factors interact in space through time. The aim of this paper is to assess the relative influence of topography and fire on the landscape patterns of a large forested area located in Sierra de Gredos (Central Spain) through time. A series of Landsat MSS images from 1975 to 1990, and a digital elevation model (DEM) were used to map fires, assess topographical complexity and evaluate changes in landscape composition and structure. Functional regions across the entire landscape were identified using different classification criteria (i.e., percentage burned area and topographic properties) to model topographic and fire impacts at regional scales. A canonical variance partition method, with a time series split-plot design, quantified the relative influence and co-variation of topography and fire on land cover patterns through
\end{abstract}

Electronic supplementary material The online version of this article (doi:10.1007/s10980-008-9228-5) contains supplementary material, which is available to authorized users.

O. Viedma $(\bowtie)$

Department of Environmental Sciences, Universidad de Castilla-La Mancha, Avd/ Carlos III, s/n, 45071 Toledo, Spain

e-mail: olga.viedma@uclm.es time. Main results indicated that analyzing portions of the landscape under similar environmental conditions and fire histories, the effects of different fire regimes on the spatio-temporal dynamics of main land covers can be highlighted. However, the impact of fire on landscape patterns was high variable among regions due to the different regeneration abilities of main land covers, the topographic constraints and the fire histories of each region. Hence, broad patterns of fire related variance and co-variation with topography emerged across the entire area due to the different conditions of each landscape portion in which this large Mediterranean landscape was divided.

Keywords Landscape patterns - Forest fires . Topography - Canonical variance partition method . Co-variation · Landscape classifications

\section{Introduction}

One of the major challenges in ecology is to understand the interactions among abiotic, biotic factors and disturbances in driving landscape patterns (i.e., composition and structure) (Urban et al. 1987; Wimberly and Spies 2001). Fire introduces very different dynamics over large areas, as it tends to be differentially distributed in space, burning more frequently certain topographic positions and land cover types than others (Vázquez and Moreno 2001; Mouillot et al. 2003). On the other hand, 
environmental factors, such as topography and soil, determine site productivity and resource availability, thereby creating diverse patterns in vegetation composition and structure (Swanson et al. 1998). Indirectly, topography shapes landscapes through its impact on disturbance regimes and potential successional pathways (Agee 1993; Parisien et al. 2006). Furthermore, specieś life histories, local abundances and patterns interact with the spatial and temporal structure of driving factors controlling species distribution (Moloney and Levin 1996). Consequently, the spatial and temporal heterogeneity of disturbed landscapes is the result of a strong interaction among fire, topography and landscape components (Perry 1995). However, our understanding of how topography and disturbance interact to form landscape patterns at broad scale is still limited. This paper focuses on this issue, analyzing how topography and fire shape the landscape patterns of a large Mediterranean forested area across a range of landscape portions classified according to different criteria, and through time.

The relationship among topography, disturbances, and landscape components is reciprocal (Turner et al. 1993) and changes at several organizational levels or spatial extents (Swanson et al. 1998). For this reason, these functional interactions have been studied from many perspectives and at different scales. Some studies have assessed the role of fire occurrence and topographic constraints on the dynamic of burned vegetation at local scale (Viedma et al. 1997; DíazDelgado et al. 2002); whereas others have study the effects of topography and pre-fire vegetation conditions on fire occurrence (Podur et al. 2003; Genton et al. 2006; Yang et al. 2007; Riaño et al. 2007), fire spread (Agee 1993; Perry et al. 1999; Mermoz et al. 2005) and fire severity (Broncano and Retana 2004; Alexander et al. 2006; Lentile et al. 2006) at broader scales. In spite of the different spatial extents of the sampling designs, these approaches focus only on fire events; and they are not appropriate when the aim is to assess the role of fire occurrence and topographic constraints on vegetation dynamic at regional scales. To accomplish this, the minimum sampling unit must consider the spatial context of burned areas (i.e., unburned and burned patches), and different classification criteria for aggregating landscape sampling units are needed to reduce variability intra-regions (Ohmann and Spies 1998; Wimberly and Spies 2001; Allen et al. 2005).
Time scales of disturbance frequency and recovery are also important in the system response to fire impacts (Turner et al. 1993; Perry 1995; Peterson 2002). The spatial interaction between fire and landscape composition and structure is not constant over time (Güss 2000). Because of the temporal relationship between fire and landscape may be uncorrelated or delayed in time, studies based on continuous time series are needed (Viedma et al. 2004; Pickett et al. 2005). Several works have analyzed the spatial patterns imposed by fire on based on chronosequences of disturbed sites by time since last disturbance (Schroeder and Perera 2002; Moritz 2003). However, any general insight about the dynamical role of fire on landscape configuration cannot be obtained from such temporal approximation due to the full complexity of spatio-temporal changes in vegetation composition and structure following fire across large areas (Baker 1989; Acevedo et al. 1995; Carmel et al. 2001; Peterson 2002). In this sense, the most common problem to assess dynamic patterns on landscape rests on the lack of an adequate statistical framework that incorporates simultaneously the spatial and temporal scale dependences of driving factors (Fortin et al. 2003). Accordingly, statistical methods able to quantify the relative influence and interactions of factors in space and time are required (Bocard et al. 1992; Anderson and Gribble 1998).

The goal of this research is to quantify the relative influence of topography and fire and their co-variation on the landscape patterns (i.e., composition and structure) of a large forested area located in Central Spain. To accomplish this, different portions of the landscape, defined by different classification criteria, were analyzed using a canonical variance decomposition method, Specifically, I tested the relationship between landscape, fire and topography and their interactions based on the following hypotheses:

(1) High levels of environmental heterogeneity and/ or sampling designs covering large areas have failed in accounting for the effects of disturbances (i.e., forest fires) on landscape patterns in comparison with other shaping factors (Bucini and Lambin 2002). Then, analyzing portions of the landscape under similar environmental conditions and fire histories, could highlight the effects of different fire regimes on 
the spatio-temporal dynamics of main land covers in each sampled landscape portion (Wimberly and Spies 2001; Rollins et al. 2002).

(2) As physiographic conditions, land cover patterns and fire histories are not distributed homogeneously over large areas. I expect to find broad patterns of topography and fire related variance across the entire landscape, which will be explained by the different environmental conditions and fire histories of each landscape portion (Wimberly and Spies 2001).

\section{Methods}

The study site

The study area $(518,331$ ha) is located in Sierra de Gredos (province of Avila, Spain); UTM coordinates 4430-4484 and 277-372 in the zone $30 \mathrm{~N}$ (Fig. 1). The area is mountainous, with elevations up to 2,200 $\mathrm{m}$ and a strong gradient from the Southeast to the Northwest. The potential vegetation of the area corresponds mainly to four different types (RivasMartínez 1987): sclerophyllous oak forest (Pyro bourgaeanae-Quercetum rotundifoliae) from the lowest altitudes up to $600 \mathrm{~m}$; humid deciduous oak forest (Arbuto unedonis-Quercetum pyrenaicae) at 600-800 m; sub-humid deciduous oak forest (Luzulo forsteri-Quercetum pyrenaicae) at 800-1,600 $\mathrm{m}$ and woody-legume shrublands (Cytiso purganti-Echinospartetum barnadessi) above $1,600 \mathrm{~m}$. Despite the differences in temperature and precipitation indicated by these vegetation units, pastures, shrublands and managed pine woodlands are abundant in the landscape. At lower and middle altitudes, Pinus pinaster Aiton is the main species, whereas at higher elevations Pinus sylvestris $\mathrm{L}$. is the dominant.

Fire mapping and land cover maps

A discontinuous series of Landsat Multispectral Scanner (MSS) images for the period 1975-1990 (13 images) and a digital elevation model (DEM) data were processed to derive land cover types and topographic information for the study area, respectively. The MSS images used were from the satellites Landsat 1-5. Each annual image was chosen from summer to fall to cover the fire season, and to avoid shadow effects caused by topography and/or clouds. The images were geometrically and radiometrically corrected, and georeferenced to topographic maps at 1:50,000 scale with an error of less than 1 pixel (79 m) (0.5-0.7 pixels) (ENVI 1999). All images were converted to apparent reflectances and an empirical atmospheric normalization was carried out to minimize the effects of the different atmospheric conditions among them (ENVI 1999). To avoid the radiometric effects of relief, a non-Lambertian model was applied to separate the signal due to the ground cover from noise attributable to terrain variations (García-Haro et al. 2001). To accomplish this correction a digital terrain model (DTM) with lines at $100 \mathrm{~m}$ (Vázquez and Moreno 2001) was resampled at the same spatial resolution as the MSS images $(79 \mathrm{~m})$.

After that, fires occurred during the period 19761990 were mapped based on the normalized difference vegetation index [NDVI $=($ MSS4 - MSS2)/ (MSS4 + MSS2)]. The fire maps were derived from a series of three NDVI images corresponding to the prefire year and the 2 years following the fire, although in some years, the discontinuity of the temporal series forced us to compare the nearest (preand postfire) images available. The difference between the postfire NDVI and the prefire NDVI images identified areas which were likely burned. Specifically, a sudden decrease in NDVI values between images before and after fire was expected. I also considered the NDVI difference between the second postfire year and the first year after fire to quantify rapid changes in vegetation during the two following years after fire; although such changes were less predictable than the abrupt drop of the NDVI values between the prefire and postfire images (Salvador et al. 2005). Later, a multitemporal unsupervised classification using the two difference images was carried out to extract the burned lands of each year (Viedma et al. 2006). To verify the firemapping procedure, a map of the fires that occurred in the central portion of the study area was reconstructed using aerial photographs for 1957, 1972 and 1990 (scales 1:30,000; 1:25,000 and 1:20,000, respectively). (Vázquez and Moreno 1998) (Fig. 1). Fire scars $(>4$ ha) were detected from aerial photographs taken in 1972 and assessed in field work. Fire perimeters were digitised, geometrically corrected and converted to a raster format at a common pixel 
Fig. 1 Location of the study site at Sierra de Gredos (Central Spain) and map of elevation from the digital elevation model (DEM). The frame in the centre of the image shows the control area analysed by photo-interpretation, and the $10 \times 10 \mathrm{~km}$ grid represents the sites from which all the analyses were carried out

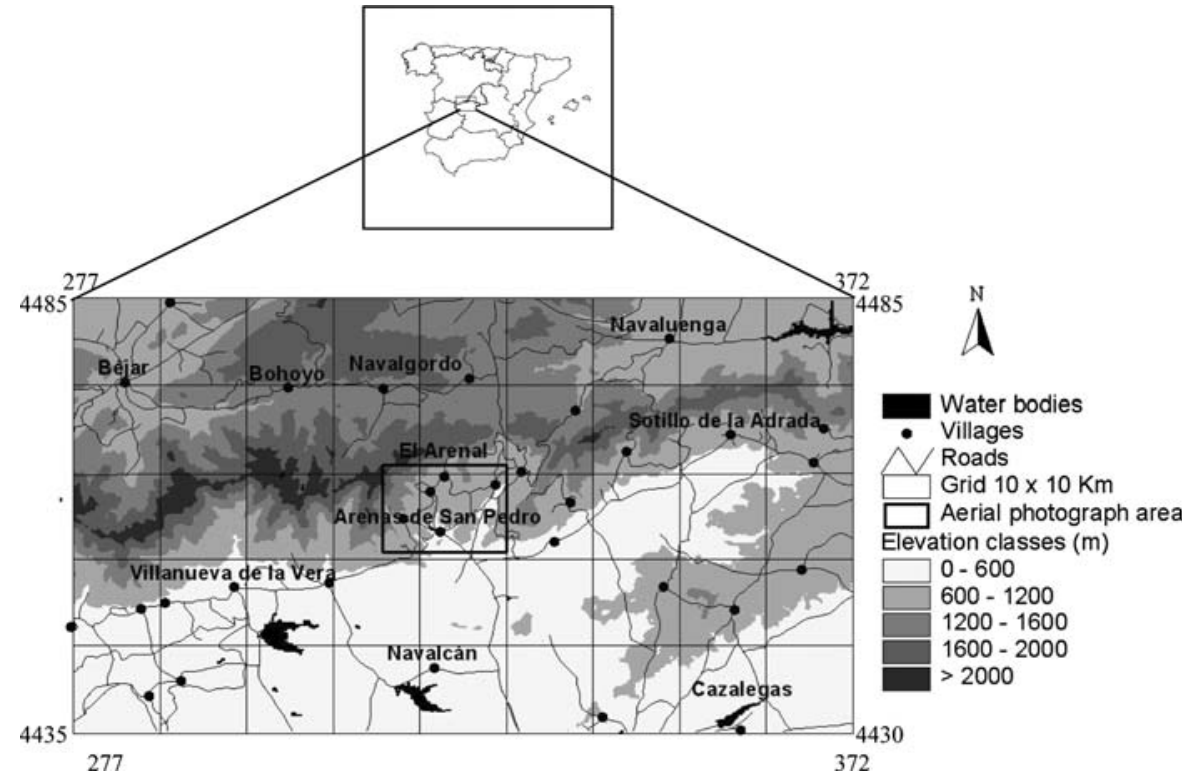

size of $79 \mathrm{~m}$ in IDRISI 32 (Eastman 1999). For the rest of the study area, annual statistics recorded by the Forest Service (ICONA) in a UTM lattice of $10 \times 10 \mathrm{~km}$ were also available for the period 1975-1990 (Fig. 1).

Finally, land-cover maps were based on a classification system applied uniformly over the time series. Annual unsupervised classifications were combined with a knowledge-based method that used decision rules and topographic stratification of the main land use/land cover (LULC) types to relate spectral classes with real land cover types (Viedma et al. 2006). Main land covers identified were: deciduous forest, pine woodland, shrubland, pasture, cropland, dehesa (managed pastures with sparse oak trees), bare soil, urban areas and water body. The accuracy of the annual classifications was assessed comparing each image with the CORINE map of 1987 using confusion matrices, and extracting the Kappa Index of Agreement (KIA) in IDRISI 32 (Eastman 1999). The overall accuracy of the annual LULC classifications produced a mean Kappa value of 0.82 ( \pm 0.09 SD) (Viedma et al. 2006). However, the KIA fails to specify reasons for the disagreement between two maps, because it confounds information about the quantity of each category in the maps with information about the location of each category in the maps (Pontius et al. 2000; Pontius and Millones 2008). According to these authors, two components of disagreement (i.e., quantity and location) for revealing direct information about the differences between relevant maps were calculated. The results indicated that the mean location and quantity disagreement values of the classification images respect to the CORINE map of 1987 were $7.15( \pm 0.51 \mathrm{SD})$ and $6.62( \pm 0.24 \mathrm{SD})$, respectively, for the period analyzed (1975-1990).

The sampling design and variables measured

To appropriately assess the relationship between topography, fire and landscape patterns at regional scales, I defined sampling units that took into account the spatial context of burned areas and they were scale independent (i.e., there was a lack of spatial autocorrelation in the measured variables) (Wu et al. 2002). For the first assumption, an extension area greater than the largest fire event occurred during the temporal series (about 5,000 ha) was required. For the second one, I explored the behaviour of several landscape metrics at different spatial extents. To accomplish this, I selected randomly $25 \%$ of fire events $(n=30)$, drew buffers of different size around them (from 0.5 to $15.0 \mathrm{~km}$ of perimeter at each $0.5 \mathrm{Km}$ ), and calculated several landscape metrics in each buffer size using a reference land cover map (ESRI 1999). The averaged values of such metrics for the 30 random sites at each spatial extent were 


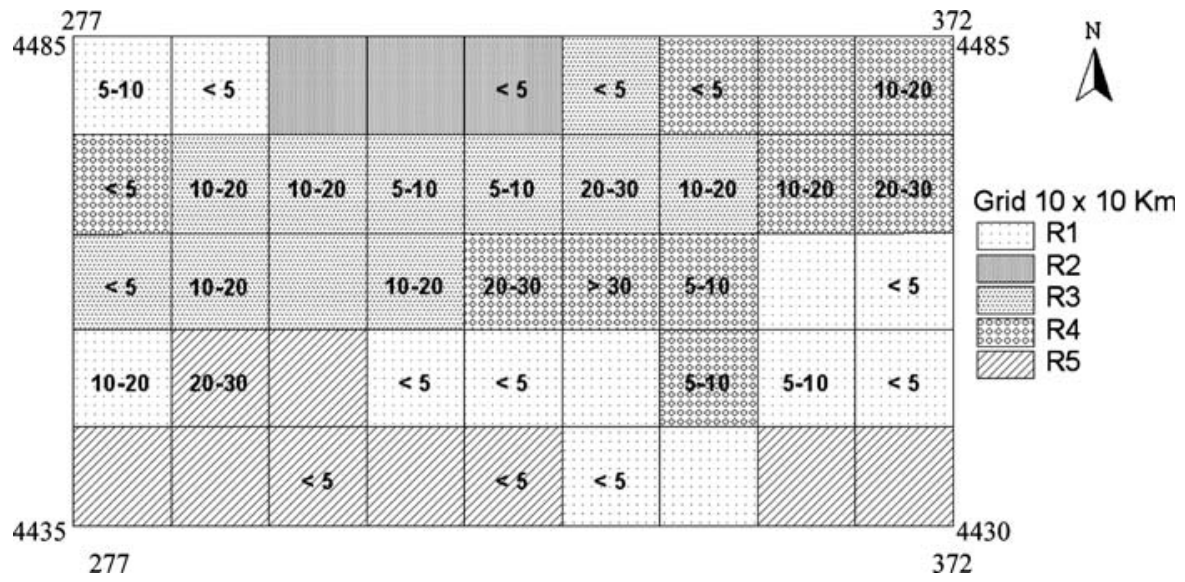

Fig. 2 Spatial arrangement of the regions (R1-R5) obtained from the cluster analysis (CA) applied on topographical variables, and burned sites classified according to the

plotted; and as it would be expected, some landscape metrics were sensitive to the increase of the spatial extent (not shown). At buffers of $10 \mathrm{~km}$ all the spatial metrics did not change reaching a plateau. Hence, I decided to divide the study area into a continuous lattice of 45 sites of $10 \times 10 \mathrm{~km}$ to envelop the greatest fire and to assure that landscape patterns were captured by each sampling site avoiding spatial autocorrelation.

Once the sites of $10 \times 10 \mathrm{~km}(\mathrm{n}=45)$ were defined, multiple sampling designs using different classification criteria were established. The broader classifications considered all sites $(n=45$; both burned and unburned sites), and only burned sites $(\mathrm{n}=32)$ (Fig. 2). In the next step, I classified sites according to the percentage of burned area during 1976-1990 [i.e., $<5 \% \quad(\mathrm{n}=13), 5-10 \% \quad(\mathrm{n}=6)$, $10-20 \%(\mathrm{n}=8), 20-30 \%(\mathrm{n}=4)$ and $>20 \%(\mathrm{n}=5)$ (this latter included the same sites than the previous class $(20-30 \%)$ plus one site with $>30 \%$ of its area affected by fire)] (Fig. 2). Later, sites were classified according to their topographical properties using an agglomerative cluster analysis (CA) identifying five regions $[R 1(n=12), R 2(n=3), R 3(n=11), R 4$ $(\mathrm{n}=10)$ and R5 $(\mathrm{n}=9)$ ] (Fig. 2 and Supplementary material). Finally, the finest classification was obtained separating sites with different percentages of burned area from the topographical region to which they belonged [i.e., R1 with $1-5 \%$ burned area $(\mathrm{n}=6), \mathrm{R} 15-10 \%(\mathrm{n}=3), \mathrm{R} 31-5 \%(\mathrm{n}=2), \mathrm{R} 3$ $5-10 \% \quad(\mathrm{n}=2)$, R3 $10-20 \% \quad(\mathrm{n}=5), \mathrm{R} 4 \quad 1-5 \%$ $(\mathrm{n}=2), \mathrm{R} 45-10 \%(\mathrm{n}=2), \mathrm{R} 4>20 \%(\mathrm{n}=3)$ and percentage of burned area during 1976-1990 (i.e., <5\%, 5-10\%, 10-20\%, 20-30\% and >30\%)

R5 1-5\% ( $=3$ )] (Fig. 2). Statistical analyses were applied to each group of sites.

The analysis of landscape composition (i.e., land cover abundances) in space and time was carried out by calculating annually the hectares occupied by main land cover types in each site $(n=45)$. Landscape structure was assessed by computing a set of spatial metrics able to characterize main properties of landscape patterns (i.e., spatial fragmentation of land cover patches, patch shape complexity, spatial distribution of land covers and landscape diversity) (McGarigal and Marks 1995). In this sense, the metrics selected were the following: (i) patch density (PD) and mean core area (MCA) for fragmentation; (ii) mean shape index (MSI) for patch shape complexity, (iii) interspersion and juxtaposition index (IJI) and mean nearest neighbor (MNN) for the spatial distribution of patches, and (iv) Shannońs diversity index (SHDI) for landscape diversity. These spatial metrics were calculated yearly during 19751990 using FRAGSTATS software (McGarigal and Marks 1995). To characterize the fire history of each site, I calculated annually: (i) burned area (immediate fire effects), (ii) accumulated burned area (long term fire effects), (iii) burned area classified by time since fire (1-5 years old) (regeneration process effects), and (iv) annual burned area plus burned area classified by time since fire (i.e., less equal $1-5$ years old) (both immediate fire effects and regeneration process). After extracting main variables from the discontinuous series (13 images for a period of 16 years), a cubic splines interpolating method was 
applied (CurveExpert 1.37). Mean altitude, slope and direct solar radiation were calculated from the DEM to account for physical topography of each site using ArcView 3.2. (Solar Analyst Extension) (ESRI 1999). Finally, to assess topographic complexity/patterns, landscape metrics were calculated on topographic patches created from the simultaneously combination of elevation classes at each $200 \mathrm{~m}$, slope classes at each 10\%, and aspect classes (flat plus 8 aspect classes at each $22.5^{\circ}$ ), obtaining similar landscape structural features as from land covers (fragmentation, shape complexity, distribution and diversity).

Determining the influence of topography and fire history on landscape patterns at regional scales

The independent influence of topography and fire, and their co-variation on the spatiotemporal variability of landscape patterns was assessed by partial redundancy analyses (pRDA) with a time series splitplot design (terBraak and Šmilauer 1998). RDA is a canonical or constrained principal components analysis (PCA) that extract patterns from the explained variation of environmental variables (i.e., direct gradient analysis). When RDA includes co-variables (i.e., pRDA), the effect of these variables on the response of dependent variables is partialled out, and the sum of canonical eigenvalues represents the variance explained by the environmental variables after accounting for the co-variables (ter Braak and Šmilauer 1998). This method replaces environmental variables by their residuals after regressing each environmental variable on co-variables, and later fits the residuals to the dependent data matrix. Partial RDA allowed decomposing the inertia (variance) into various components attributed to different sets of explanatory variables (Bocard et al. 1992; Wimberly and Spies 2001; Cushman and McGarigal 2002; Cushman and Wallin 2002). In this study, we decomposed variance attributable to explanatory variables as following:

[1] $\mathrm{T}$ (Topographic Variation): variation explained by topography. RDA models without covariables.

[2] TIF (Only Topographic Variation): variation explained only by topography, independent of fire history (Partial RDA: fire as co-variable).
[3] F (Fire Variation): variation explained by fire history. RDA models without co-variables.

[4] FIT (Only Fire variation): variation explained only by fire history, independent of topography (partial RDA: topography as co-variable).

[5] $\mathrm{T} \cap \mathrm{F}$ (Interaction/Co-variation between Topography and Fire): the shared/confounded variation explained simultaneously by topography and fire ([1]-[2] and/or ([3]-[4]).

[6] $\mathrm{T}+\mathrm{F}$ (Total explained variance): The variance explained by the sum of the following variances: $\mathrm{T}|\mathrm{F}+\mathrm{F}| \mathrm{T}+\mathrm{T} \cap \mathrm{F}$.

A stepwise selection method for entering variables was applied using a Monte Carlo permutation test (999 runs) for significance testing in CANOCO software (terBraak and Šmilauer 1998). The splitplot method is a hierarchical design that allows quantifying the spatio-temporal dimension of the phenomenon studied by means of the whole-plots (each site) and the split-plots (time series for each site). The effect of environmental variables that vary between whole-plots (i.e., topography) can be tested by permuting whole plots while keeping the splitplots of each whole-plot together. The effect of environmental variables that vary within whole-plots (i.e., the temporal dimension of fire history) can be tested by permuting split-plots within whole-plots without permuting whole-plots. The temporal dependence of fire on previous fire events, was taken into account indicating dependent split-plot permutations across whole plots.

RDA and pRDA analyses were run for the period 1981-1990 (10 years) to take into account burned area 5 years old, and they were applied to different portions of the landscape according to different classification criteria: (i) all sites, (ii) only burned sites, (iii) burned sites classified according to the percentage of burned area, (iv) sites classified according to the topographical region, and (v) burned sites classified according to the percentage of burned area split by the topographical region at which they belonged. RDA and pRDA models were calculated separately for landscape composition and structure. In all analyses, scaling was optimized for intersample distance and variables were log-transformed $\left[\mathrm{Y}^{\prime}=\log (\mathrm{Y}+1)\right]$ to lessen the effect of skewed distributions. I extracted both the total explained variance for all dependent variables together from 
eigenvalues, and the variation explained for each land cover type or spatial metrics from the cumulative fit per species table in CANOCO output (p. 176 in the CANOCO 4.5 manual).

Finally, I related by stepwise multiple linear regression (MLR) averaged topographical conditions, fire histories, land cover abundances and structure of each smallest sampled region during 1981-1990 with fire related variance $(\mathrm{F} \mid \mathrm{T})$, topography $(\mathrm{T} \mid \mathrm{F})$, and their co-variation $(\mathrm{T} \cap \mathrm{F})$ for testing the existence of broad scale patterns of spatio-temporal explained variance over the entire area.

\section{Results}

Fire regime

From 1976 to 1990, 121 fires were recorded, which swept across a total area of 29,144 ha ( $\approx 8 \%$ of the forested area). The $63 \%$ of fires burned mainly shrublands, $30 \%$ were fires of pine woodlands and only $7 \%$ fires of pastures. Of the fires, $65 \%$ were caused by people (45\% intentional and $20 \%$ negligences); $32 \%$ were caused by unknown sources and only $3 \%$ by lightning. Mean fire frequency was nine fires per year, and the mean annual rate of burned area was $0.7 \%$, thus corresponding to 142 years of fire rotation period (time needed to burn the entire forested area). Fire size ranged between 13 and
5,008 ha. According to Forest Service fire statistics, the most common fire size ranged between 50 and 100 ha, whereas the Landsat fire maps indicated that small fires $(<50 \mathrm{ha})$ were the most frequent (Fig. 3). The coarse spatial and radiometrical resolution of Landsat MSS images detected partially burned areas between 50 and 100 ha underestimating the most common fire size, and biasing fire size estimation to the smallest fire size (0-50 ha). As expected, the degree of detection improved as the size of fires increased (Fig. 3). The mapping procedure produced an averaged agreement of $81 \%( \pm 4.4 \mathrm{SD})$ for the annual burned area and $89.5 \%( \pm 4.9 \mathrm{SD})$ for the annual fire number with the fire maps based on aerial photography. The accuracy concerning the Forest Service fire statistics was $86 \%( \pm 2.3 \mathrm{SD})$ and $75 \%$ $( \pm 1.5 \mathrm{SD})$ for annual burned area and number of fires, respectively (Viedma et al. 2006).

Determining the influence of topography and fire history on landscape patterns at regional scales

In partial RDA (pRDA) models at broader classifications [i.e., all sites $(\mathrm{n}=45$ sites) in one hand, and burned sites $(n=32)$ in the other], the total explained variance $(\mathrm{T}+\mathrm{F})$ of landscape composition was $45 \%$ and $56 \%$, respectively (Table 1). From total variance, topography $(\mathrm{T} \mid \mathrm{F})$ explained around $75 \%$, in both cases, turning into the main shaping factor of landscape composition (Table 1). Separating results

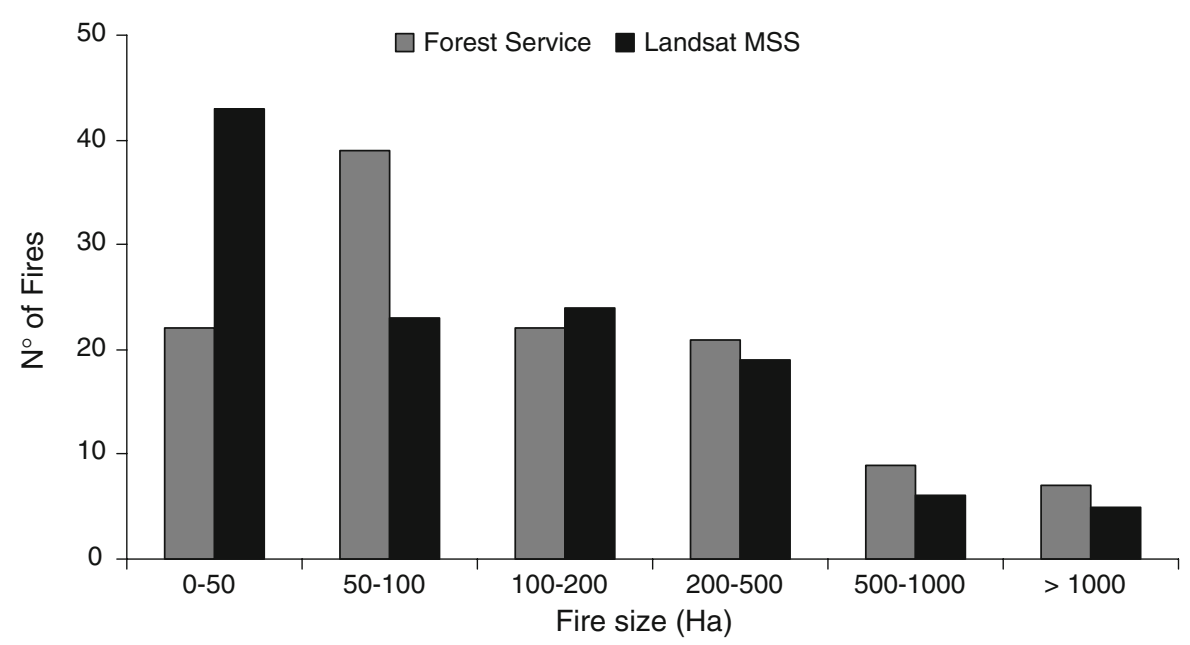

Fig. 3 Distribution of the number of fires according to different fire size groups following the fire statistics of the National Forest service of Spain, and the results of the fire mapping process using a series of Landsat MSS images from 1975 to 1990 
Table 1 Total explained variance extracted from eigenvalues of partial redundancy analyses (pRDA), according to the sampling design and the method of partition variance used

\begin{tabular}{lcc}
\hline $\begin{array}{l}\text { Sampling design and method of } \\
\text { partition variance }\end{array}$ & $\begin{array}{c}\text { Landscape } \\
\text { composition }\end{array}$ & $\begin{array}{c}\text { Landscape } \\
\text { structure }\end{array}$ \\
\hline All sites & & \\
$\mathrm{T} \mid \mathrm{F}$ & $34( \pm 0)$ & $38( \pm 0)$ \\
$\mathrm{F} \mid \mathrm{T}$ & $6( \pm 0)$ & $2( \pm 0)$ \\
$\mathrm{T} \cap \mathrm{F}$ & $5( \pm 0)$ & $1( \pm 0)$ \\
$\mathrm{T}+\mathrm{F}$ & $45( \pm 0)$ & $41( \pm 0)$ \\
Burned sites & & \\
$\mathrm{T} \mid \mathrm{F}$ & $42( \pm 0)$ & $43( \pm 0)$ \\
$\mathrm{F} \mid \mathrm{T}$ & $6( \pm 0)$ & $3( \pm 0)$ \\
$\mathrm{T} \cap \mathrm{F}$ & $8( \pm 0)$ & $0( \pm 0)$ \\
$\mathrm{T}+\mathrm{F}$ & $56( \pm 0)$ & $46( \pm 0)$ \\
Groups of burned sites & & \\
$\mathrm{T} \mid \mathrm{F}$ & $62( \pm 12)$ & $72( \pm 11)$ \\
$\mathrm{F} \mid \mathrm{T}$ & $6( \pm 1)$ & $10( \pm 8)$ \\
$\mathrm{T} \cap \mathrm{F}$ & $23( \pm 13)$ & $10( \pm 8)$ \\
$\mathrm{T}+\mathrm{F}$ & $91( \pm 29)$ & $91( \pm 36)$ \\
Topographical regions & & \\
$\mathrm{T} \mid \mathrm{F}$ & $53( \pm 13)$ & $77( \pm 10)$ \\
$\mathrm{F} \mid \mathrm{T}$ & $11( \pm 13)$ & $6( \pm 4)$ \\
$\mathrm{T} \cap \mathrm{F}$ & $23( \pm 20)$ & $12( \pm 13)$ \\
$\mathrm{T}+\mathrm{F}$ & & $95( \pm 40)$ \\
Groups of burned sites split by & topographical regions \\
$\mathrm{T} \mid \mathrm{F}$ & $34( \pm 17)$ & $40( \pm 19)$ \\
$\mathrm{F} \mid \mathrm{T}$ & $27( \pm 26)$ & $15( \pm 14)$ \\
$\mathrm{T} \cap \mathrm{F}$ & & \\
$\mathrm{T}+\mathrm{F}$ & & \\
\hline
\end{tabular}

$\mathrm{TIF}$, variance explained only by topography after extracting the influence of fire; FIT, variance explained only by fire after extracting the influence of topography; $\mathrm{T} \cap \mathrm{F}$, co-variation or shared variance explained by topography and fire: TIF - FIT and $\mathrm{T}+\mathrm{F}$, total variance explained by only topography, only fire and their co-variation: $\mathrm{TIF}+\mathrm{FIT}+\mathrm{T} \cap \mathrm{F}$

by land cover types, only bare soil showed a certain proportion of the variance explained by fire $(15 \%)$, and only the $10 \%$ of the spatio-temporal variance of pine woodlands and shrublands was explained by the co-variation between topography and fire (Fig. 4a and c). In spite of the weak influence of fire in both the entire area and only burned sites, all canonical axes were statistically significant $(P<0.05)$. The total explained variance $(T+F)$ on landscape structure was nearly similar to landscape composition (i.e., $41 \%$ and $46 \%$ for all sites and only burned sites, respectively), but the influence of fire (FIT) and/or its co-variation with topography $(\mathrm{T} \cap \mathrm{F})$ was weaker (Table 1 and Fig. 4b and d). Only landscape diversity (SHDI) in burned sites showed certain sensitivity to fire effects (Fig. 4d).

When sites were grouped by the proportion of burned area, total explained variance $(\mathrm{T}+\mathrm{F})$ of landscape composition increased (91\%) (Table 1). Although the influence of fire (FIT) was similar as previous broad classifications, the co-variation between fire and topography $(\mathrm{T} \cap \mathrm{F})$ was higher (Table 1), and a certain trend of increase was observed as the proportion of burned area was greater (Fig. 5a). Separating results by land cover types, I could assess that bare soil was the land cover better explained by fire whereas the other ones were explained mainly by topography and the co-variation between fire and topography (Fig. 5b). In the case of landscape structure, the role of fire (FIT) was little higher than in landscape composition, but co-variation $(\mathrm{T} \cap \mathrm{F}$ ) was lower (Table 1 and Fig. 5c). Only SHDI and IJI and overall, NP and MCA were explained by fire above the averaged fire related variance (10\%) (Fig. 5d). All canonical models were statistically significant $(P<0.05)$.

As expected, when sites were grouped by the topographical region at which they belonged, the variance explained by topography $(\mathrm{T} \mid \mathrm{F})$ on landscape composition was lower, and fire effects (F/T) increased nearly double than in the previous classifications (Table 1 and Fig. 6a). Separating results by land cover types, I could observe a similar pattern of influence as previously (Fig. 6b). In the case of landscape structure, the role of fire (FIT) and its covariation with topography $(\mathrm{T} \cap \mathrm{F})$ was lower than in landscape composition, showing a behaviour very similar to the above classifications (Table 1 and Fig. 6c-d). SHDI continued being the landscape pattern better explained by the co-variation between topography and fire (Fig. 6d). All canonical models were statistically significant $(P<0.05)$.

At the finest classification, (i.e., classes of burned sites split by the region at which they belonged) the proportion of total variance $(\mathrm{T}+\mathrm{F})$ explained was 93\% (Table 1). In general, the influence of fire (F|T) and its co-variation with topography $(\mathrm{T} \cap \mathrm{F})$ on landscape composition increased, although with a high variability among sites (Table 1 and Fig. 7a). I could observe that the general pattern of influence changed in relation to previous classifications 

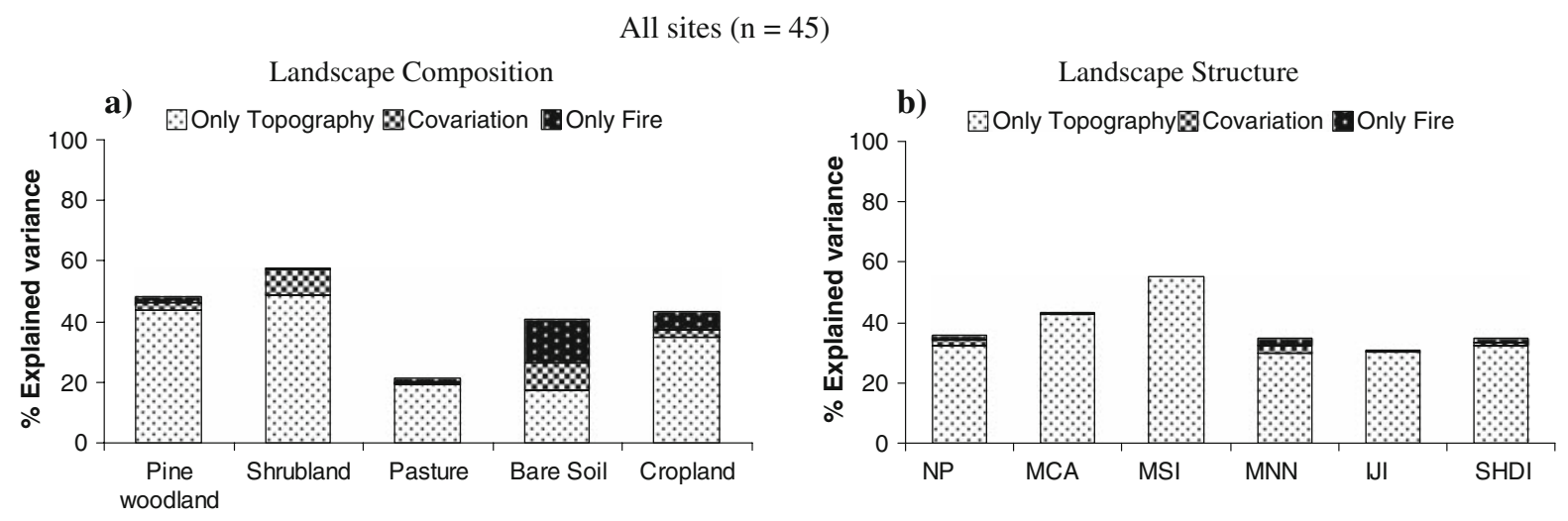

Only burned sites $(\mathrm{n}=32)$

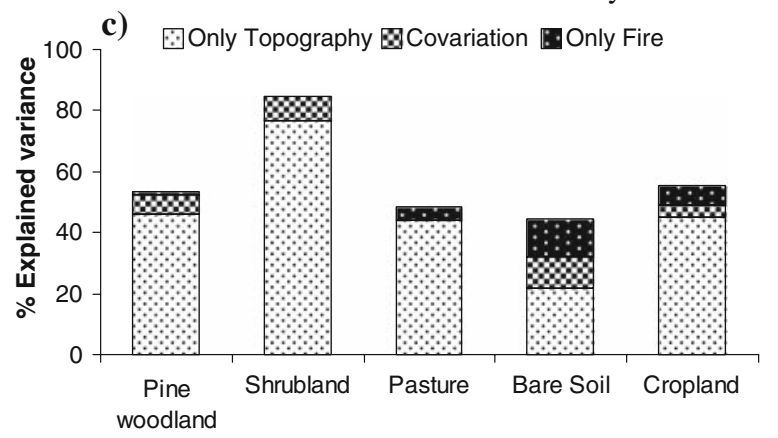

Fig. 4 Spatio-temporal variance explained by only topography $(\mathrm{T} \mid \mathrm{F})$, the co-variation between topography and fire $(\mathrm{T} \cap \mathrm{F})$ and only fire (FIT) on landscape composition (land cover abundances) and landscape structure (PD, MCA, MSI, MNN,

(Fig. 7b). Although the role of fire continued being very important in bare soil distribution, the influence of topography $(\mathrm{T} \mid \mathrm{F})$ decay and the co-variation with fire $(T \cap F)$ increased in the other land covers (Fig. 7b). In the case of landscape structure, the influence of fire (FIT) was weaker but the co-variation with topography $(\mathrm{T} \cap \mathrm{F})$ was greater than in landscape composition. Separating results by structure components, I could assess that fragmentation (NP and MCA) and diversity and distribution (SHDI and IJI) were more related to fire than other landscape metrics (Fig. 7d).

Finally, broad patterns of fire (F|T), topography $(\mathrm{T} \mid \mathrm{F})$ and co-variation $(\mathrm{T} \cap \mathrm{F})$ influence on landscape composition and structure across the entire area was assessed by multiple linear regression models (MLR) (Table 2). The spatial variability of topographic influence $(\mathrm{T} \mid \mathrm{F})$ on landscape composition and structure was not explained by any factor characterizing sampled regions $(n=9)$ (not shown). However,

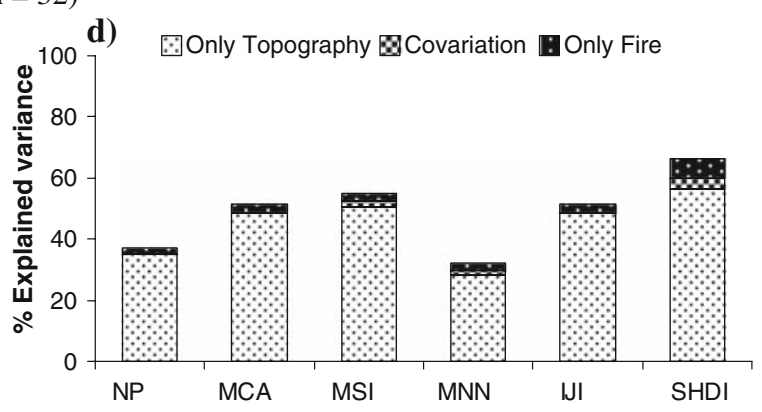

IJI and SHDI) at broad scale. (a-b) all sites $(\mathrm{n}=45 \times 10$ years $)$ and $(\mathbf{c}-\mathbf{d})$ only sites burned ( $n=32 \times 10$ years) from 1981 to 1990

regional land cover abundances, landscape structure, topographic conditions and fire history of each landscape portion were main variables explaining the variability of fire $(\mathrm{F} \mid \mathrm{T})$ and co-variation $(\mathrm{T} \cap \mathrm{F})$ influence across the entire area (Table 2). Fire history only appeared as an explanatory variable in the models related to the influence of co-variation on MCA (landscape fragmentation) and SHDI (landscape diversity) (Table 2). Finally, the variability of fire and co-variation influence on MNN and IJI was not explained by any variable related to the biophysical conditions and/or fire histories of each sampled site (Table 2).

\section{Discussion}

The landscape of the Sierra de Gredos is a dynamic system, heterogeneous in composition, structure, topography and fire, and contained different 


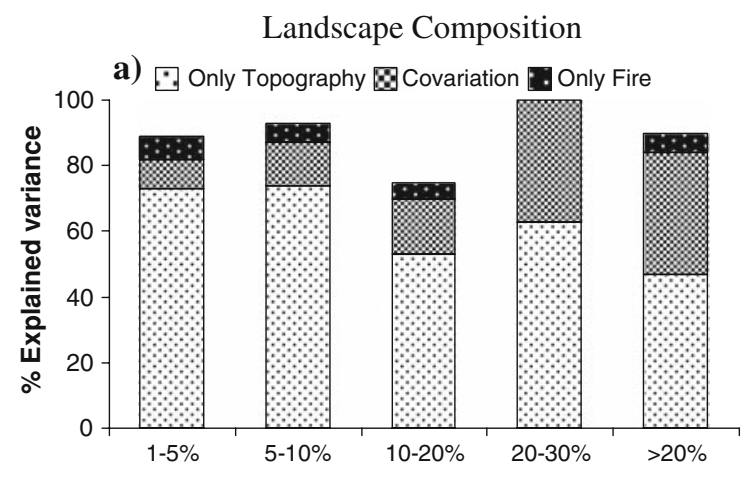

b)

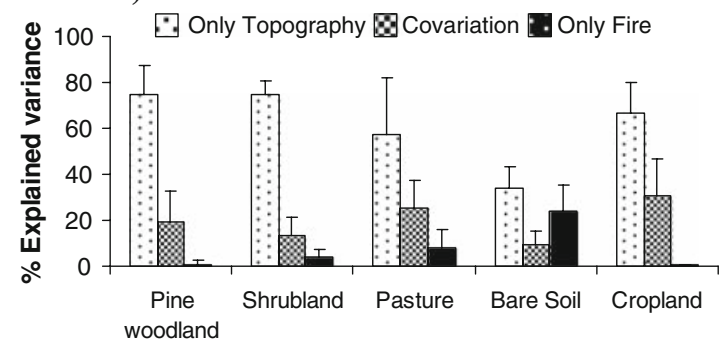

Landscape Structure

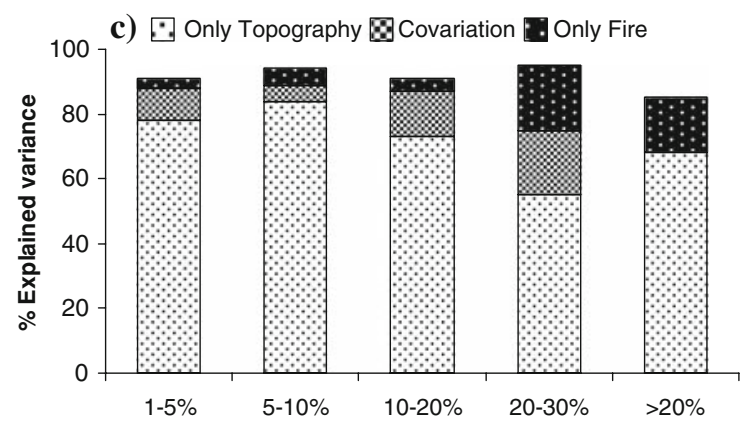

d) Only Topography $\mathbf{Q}$ Covariation Only Fire

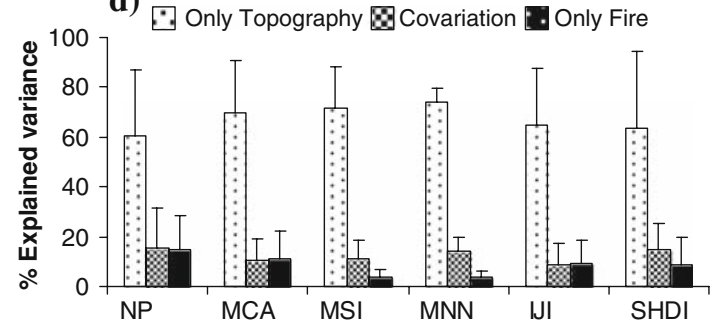

functional regions. Studies that have explicitly compared the effects of multiple ecological factors at regional scale have suggested that the dominant factors controlling vegetation patterns vary with the extension of the study area and the manner in which landscape components are characterized (Ohmann and Spies 1998; Wimberly and Spies 2001). The results of this paper indicated that aggregating
Fig. 5 Spatio-temporal variance explained by only topography $(\mathrm{T} \mid \mathrm{F})$, the co-variation between topography and fire $(\mathrm{T} \cap \mathrm{F})$ and only fire (F/T) on (a) landscape composition and (c) landscape structure (PD, MCA, MSI, MNN, IJI and SHDI) in the sites classified by the percentage of burned area for the period 1981-1990 (i.e., $<5 \% \quad(\mathrm{n}=13 \times 10), \quad 5-10 \%$ $(\mathrm{n}=6 \times 10), 10-20 \%(\mathrm{n}=8 \times 10), 20-30 \%(\mathrm{n}=4 \times 10)$ and $>20 \%(\mathrm{n}=5 \times 10))$. Mean and standard deviation bars of the spatio-temporal explained variance in (b) each land cover type and (d) landscape spatial metrics are showed from the cumulative fit per species table

sampling landscape units with high variability in environmental conditions and fire histories (i.e., all sites and burned sites), the ordination models showed a relative low predictive power, and the spatial variance explained by topography was maximum (Fig. 8a-b). When sampling landscape units reduce the variability of any of both factors through classification criteria (i.e., topographical properties and/or fire history), the ordination models explained up to $90 \%$ the total variance. The statistical role of topography continued being high, but the portion of variance explained by the co-variation with fire increased (Fig. 8a-b). However, at this organizational level of the landscape, the temporal variance explained by fire is masked by the high variability introduced by topography (in burned regions); and the variance explained by topography masked by different fire histories (in topographical regions). Finally, when sampling landscape units showed similar environmental conditions and fire histories (i.e., groups of burned sites split by the topographical region at which they belonged), the variance explained by fire and by its co-variation with topography increased very much (Fig. 8a-b). Hence, drawing conclusions about the role of driving factors on landscape components based on a set of observations at one scale, or from one organizational level, may lead to a misunderstanding of the importance of them in driving system behavior (Wiens 1989; Levin 1992; Urban et al. 1999; Pickett et al. 2005).

On the other hand, the impact of fire on each land cover analyzed was highly variable due to different regeneration abilities and land use change context. According to a previous study by Viedma et al. (2006) in the same area, land use changes and fire history explained the landscape characteristics of the entire area. Before the 1970s, fire occurrence (no fire was registered and mapped until 1970) seemed to be 

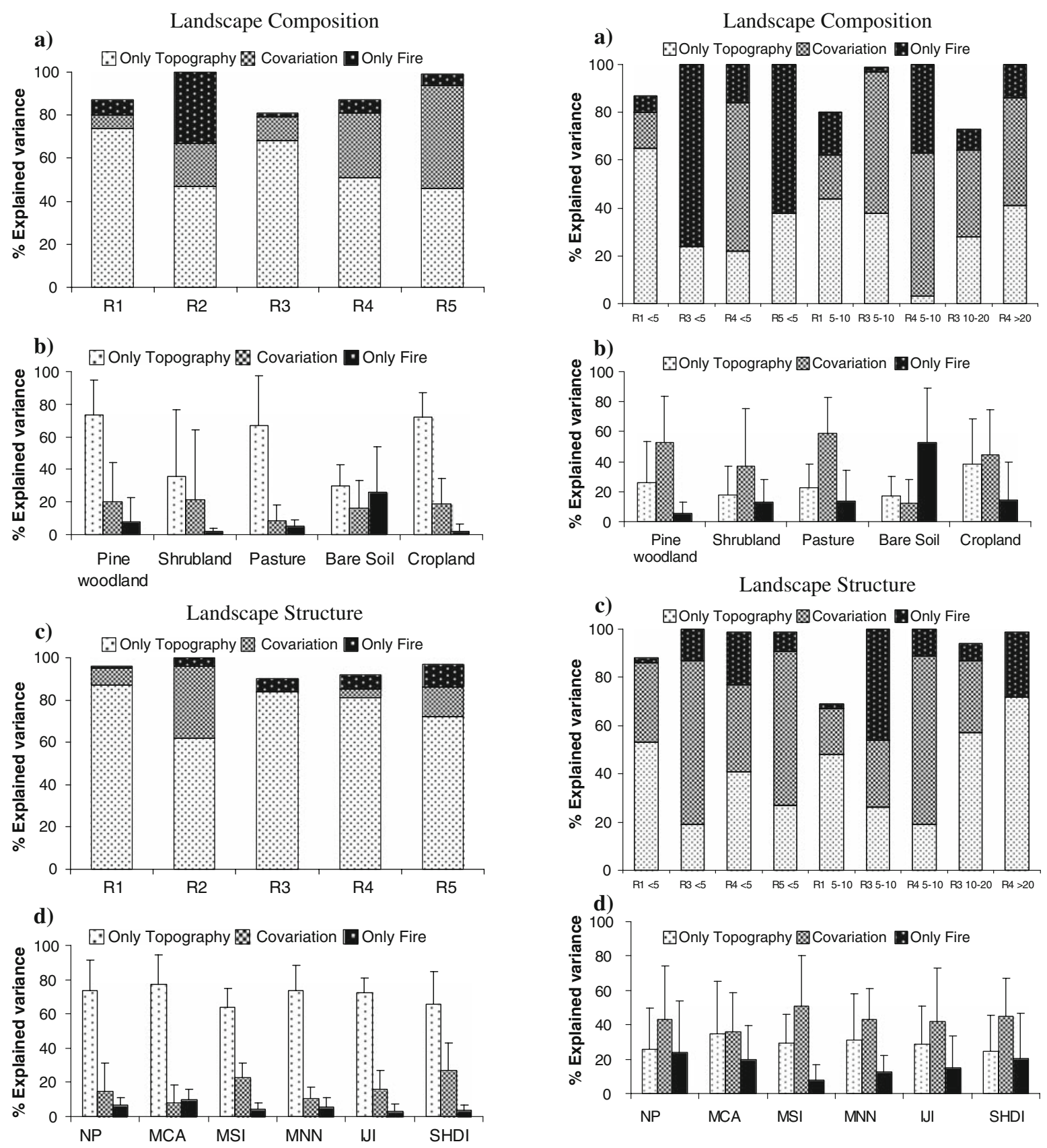

Fig. 6 Spatio-temporal variance explained by only topography $(\mathrm{T} \mid \mathrm{F})$, the co-variation between topography and fire $(\mathrm{T} \cap \mathrm{F})$ and only fire (FIT) on (a) landscape composition and (c) landscape structure (PD, MCA, MSI, MNN, IJI and SHDI) in the regions identified by cluster analysis (CA) for the period 1981-1990 (i.e., R1 $(\mathrm{n}=12 \times 10)$, R2 $(\mathrm{n}=3 \times 10)$, R3 $(\mathrm{n}=11 \times 10), \mathrm{R} 4(\mathrm{n}=10 \times 10)$ and R5 $(\mathrm{n}=9 \times 10))$. Mean and standard deviation bars of the spatio-temporal explained variance in (b) each land cover type and (d) spatial metrics obtained from the cumulative fit per species table are showed

Fig. 7 Spatio-temporal variance explained by only topography $(\mathrm{T} \mid \mathrm{F})$, the co-variation between topography and fire $(\mathrm{T} \cap \mathrm{F})$ and only fire (F/T) on (a) landscape composition and (c) landscape structure in groups of burned sites split by the topographical region at which belonged for the period 19811990 [i.e., $\mathrm{R} 1(<5 \%(\mathrm{n}=6 \times 10)$ and $5-10 \%(\mathrm{n}=3 \times 10))$; R3 $(<5 \%(\mathrm{n}=2 \times 10), 5-10 \%(\mathrm{n}=2 \times 10)$ and $10-20 \%$ $(\mathrm{n}=5 \times 10)) ; \mathrm{R} 4(<5 \%(\mathrm{n}=2 \times 10), 5-10 \%(\mathrm{n}=2 \times 10)$ and $>20 \%(\mathrm{n}=3 \times 10))$ and R5 $(<5 \%(\mathrm{n}=3 \times 10))]$. Mean and standard deviation bars of the spatio-temporal explained variance in (b) each land cover type and (d) spatial metrics are showed from the cumulative fit per species table 
Table 2 Multiple linear regression models (MLR) for explaining the spatial variability of fire (FIT) and co-variation $(\mathrm{T} \cap \mathrm{F})$ influence on landscape composition and structure among sites classified according to the percentage of burned area and split by the region at which they belonged $(n=9)$

\begin{tabular}{|c|c|c|}
\hline Landscape patterns & $\begin{array}{l}\text { Spatial variability } \\
\text { of fire influence (FIT) }\end{array}$ & $\begin{array}{l}\text { Spatial variability of co-variation } \\
\text { influence }(\mathrm{T} \cap \mathrm{F})\end{array}$ \\
\hline Pine woodland & $\begin{array}{l}\text { Pastures }(+0.61) \\
\text { MNN }(+0.36) \\
\text { MNNTOP (+0.60) } \\
\mathrm{R}^{2} 0.88^{* *}\end{array}$ & $\begin{array}{l}\text { MCATOP }(-5.3) \\
\text { SHDITOP }(-4.5) \\
\mathrm{R}^{2} 0.92 * * *\end{array}$ \\
\hline Shrubland & $\begin{array}{l}\mathrm{MSI}(-0.79) \\
\mathrm{NP}(+0.56) \\
\mathrm{R}^{2} 0.68 * *\end{array}$ & $\begin{array}{l}\text { Min. radiation }(-1.1) \\
\mathrm{IJI}(+0.68) \\
\mathrm{R}^{2} 0.72 * *\end{array}$ \\
\hline Pasture & $\begin{array}{l}\text { Mean radiation }(+0.76) \\
\mathrm{R}^{2} 0.52^{*}\end{array}$ & ns \\
\hline Bare soil & $\begin{array}{l}\mathrm{MNN}(+0.72) \\
\mathrm{R}^{2} 0.45^{*}\end{array}$ & $\begin{array}{l}\text { Pasture }(-0.68) \\
\mathrm{R}^{2} 0.39 *\end{array}$ \\
\hline Cropland & $\begin{array}{l}\text { MSI }(+0.63) \\
\mathrm{NP}(+0.52) \\
\text { Elevation }(-0.41) \\
\mathrm{R}^{2} 0.85^{* *}\end{array}$ & $\begin{array}{l}\text { Cropland }(+1.2) \\
\text { MCATOP }(-0.64) \\
\mathrm{R}^{2} 0.82 * *\end{array}$ \\
\hline NP & $\begin{array}{l}\text { Pasture }(-0.92) \\
\text { SHDI }(-0.60) \\
\mathrm{R}^{2} 0.51^{*}\end{array}$ & $\begin{array}{l}\text { Pasture }(+0.90) \\
\text { Min. radiation }(-0.45) \\
\mathrm{R}^{2} 0.75^{* *}\end{array}$ \\
\hline MCA & ns & $\begin{array}{l}\text { Accumulated burned area }(-0.64) \\
\text { Pasture }(+0.47) \\
\mathrm{R}^{2} 0.84^{* *}\end{array}$ \\
\hline MSI & $\begin{array}{l}\mathrm{NP}(+0.79) \\
\text { Min. radiation }(-0.47) \\
\mathrm{R}^{2} 0.71 * *\end{array}$ & $\begin{array}{l}\text { MSI }(-0.66) \\
\text { Pasture }(+0.47) \\
\mathrm{R}^{2} 0.71 * *\end{array}$ \\
\hline MNN & ns & ns \\
\hline IJI & ns & ns \\
\hline SHDI & $\begin{array}{l}\mathrm{NP}(-0.63) \\
\mathrm{R}^{2} 0.31^{*}\end{array}$ & $\begin{array}{l}\text { MNN }(-0.63) \\
1 \text { year old }(-1.46) \\
2 \text { years old }(+1.0) \\
\mathrm{R}^{2} 0.91 * *\end{array}$ \\
\hline
\end{tabular}

The independent variables were the averaged values of topography, land cover abundance, structure and fire history for each region. Significance of the regression model is shown by $* 0.05 \geq P>0.01$; ** $0.01>\bar{P} \geq 0.001$; *** $0.001>\bar{P}$
In this sense, human induced land use changes closely related to grazing practices through smallmanaged fires. After those years, many countries of the Mediterranean basin experienced depopulation of rural areas, traditional land uses abandonment (i.e., grazing, logging and croplands), and afforestation with conifers (Peroni et al. 2000; Moreira et al. 2001). Nowadays, most areas are poorly managed because of the expense required and the changes in perceptions and values, particularly when timber values disappear (Trabaud and Galtiè 1996). These land use changes favoured the expansion of shrublands and pine woodlands (Viedma et al. 2006), increasing the landscape fire hazard and fire occurrence (Moreno et al. 1998). interacted with topography and fire explaining the spatio-temporal dynamic of main land covers. Bare soils dominated burned areas immediately after fire, and tend to disappear as pastures recover. This succession process makes temporal dynamic of bare soils synchronic with annual burned area (Fig. 9a), and their spatial distribution more linked to fire occurrence than to the topographic constraints or any land use change. On the other hand, pastures dominated during the early first years after fire, showing a similar temporal behaviour than the burned area 1 year old (Fig. 9b). However, the spatial distribution of pastures could be explained by the 
Fig. 8 Averaged variance explained by only topography $(\mathrm{T} \mid \mathrm{F})$, the co-variation between topography and fire $(\mathrm{T} \cap \mathrm{F})$, and only fire (FIT) on (a) landscape composition and (b) landscape structure according to the landscape classifications considered in the study. Error bars showed \pm 1 standard deviation (SD)
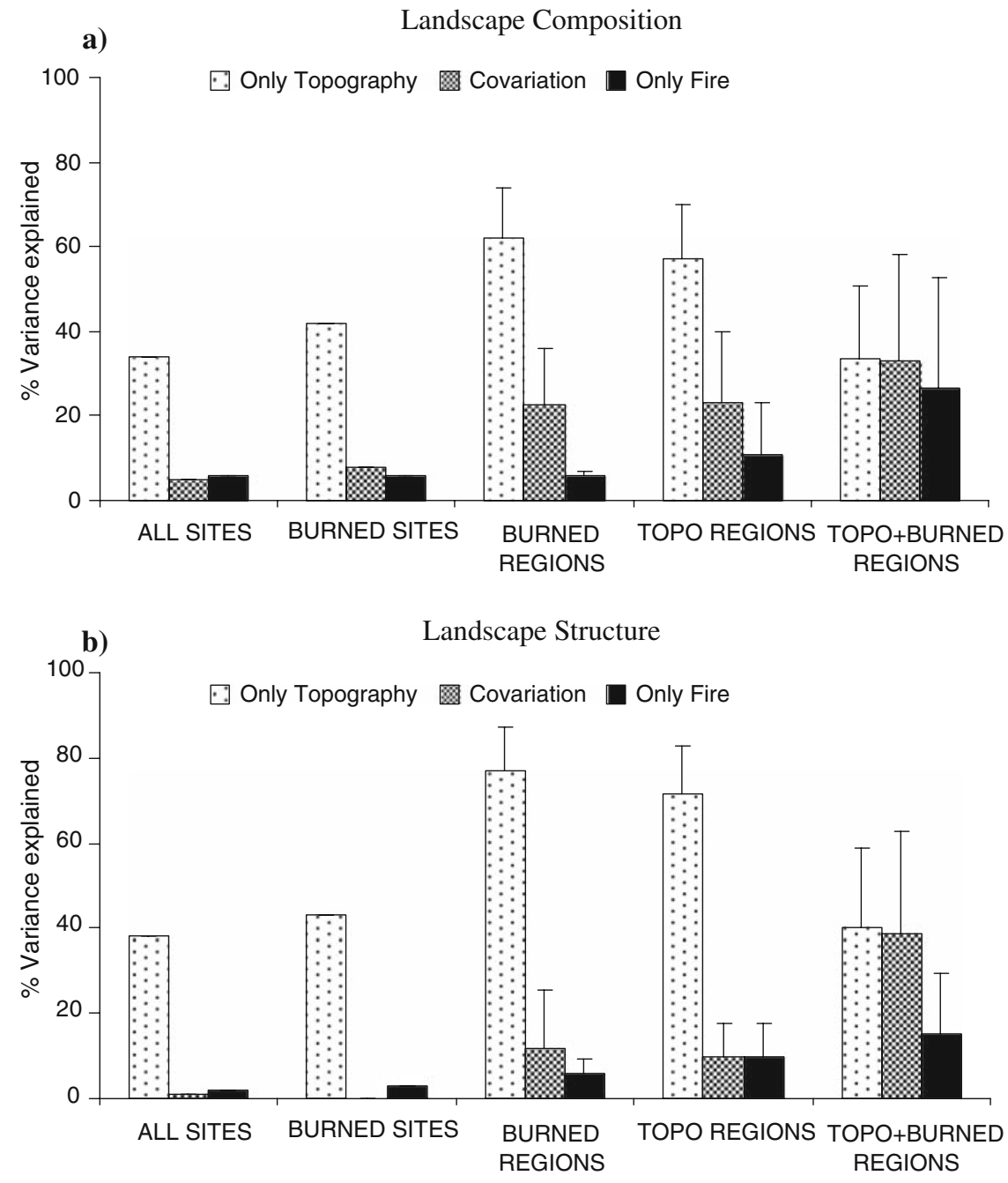

abandonment of traditional land uses (i.e., croplands and grazing) (Moreira et al. 2001; Viedma et al. 2006) apart of fire occurrence or topographic constraints. Shrublands dominated burned areas from the third year after fire (Fig. 9c) and continue being dominant in burned areas several years after fire independently of fire severity (Pérez and Moreno 1998) or land use history (Pérez et al. 2003). The spatial and temporal permanence of shrublands make their behaviour asynchronous to the fire history of burned areas; and as in the case of pastures, human land-use changes by abandonment increased their spatial extent (Romero-Calcerrada and Perry 2004; Mouillot et al. 2003; Viedma et al. 2006). Finally, the regeneration of pine woodland is not warranted in several Mediterranean burned areas (Pérez and Moreno 1998) or lasts more than 5 years to recover (maximum time recorded after fire in this study). This limitations may explain the inverse but nearly synchronuos temporal behaviour of pine woodlands with burned area 5 years old (Fig. 9d). Its spatial distribution was explained by the co-variation between fire and topography, and by afforestation practices too (Viedma et al. 2006). Hence, not only fire occurrence neither topography may explain completely the spatio-temporal dynamic of main land covers of this Mediterranean landscape, but land use changes context is an important driving factor of landscape composition and structure.

In relation to landscape structure, the landscape of Sierra de Gredos tended to become less fragmented (PD decreased and MCA increased), more contagious and compositionally more homogeneous (SHDI decreased) as result of cropland abandonment, 

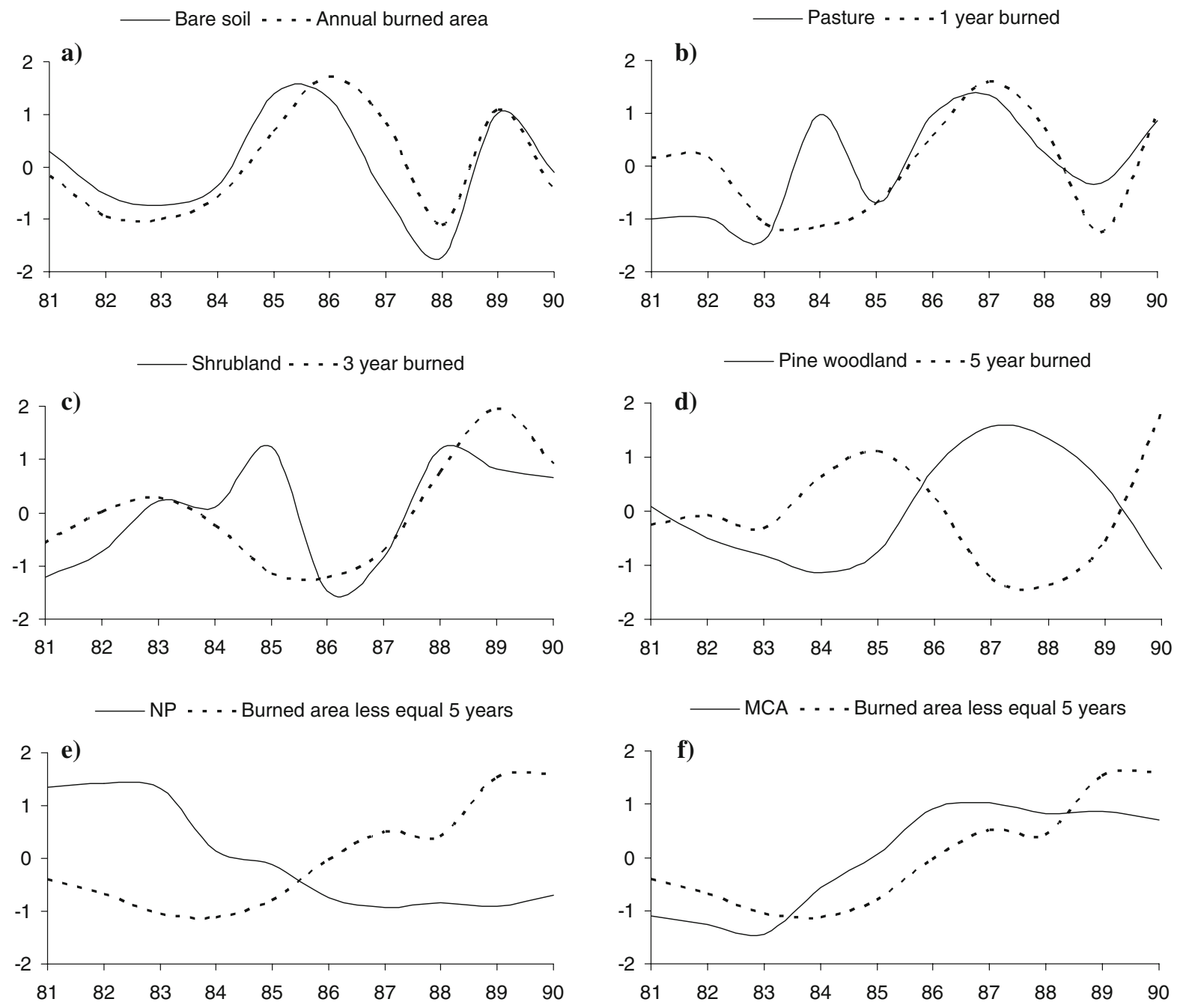

- SHDI - - - Annual burned area

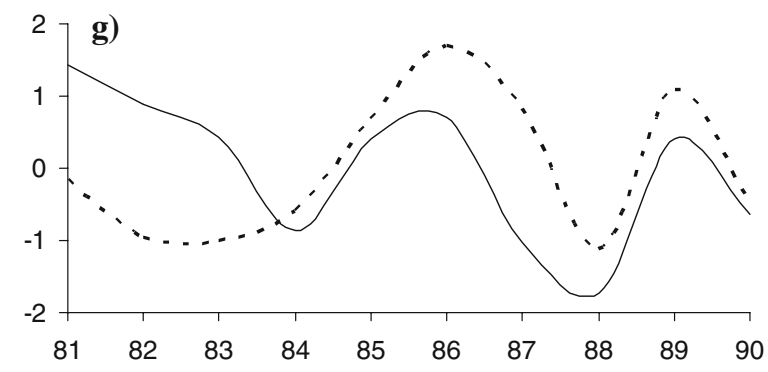

Fig. 9 Temporal dynamic of several land covers, spatial metrics and variables related to fire history for all sites $(n=45)$. For each year, spatially averaged values over the 45 sites were standardized to mean 1 and standard deviation 0 over time

forestation with conifers and the spatial dominance of shrublands after fire (Viedma et al. 2006). The results obtained indicated that NP and MCA, the landscape metrics more related to fragmentation among those analysed in this study, and SHDI, related to the diversity of landscape, were the patterns better explained by fire, showing a temporal dynamic closely related to the regeneration process and 
immediate fire effects, respectively (Fig. 9e-g). Hence, fire create spatiotemporal patterns that act simultaneously with other human-induced processes with possible feedbacks among them (Moreira et al. 2001; Mouillot et al. 2003).

Finally, many studies based on fire-landscape relationship have shown how fire produced unequal impacts over large areas due to the different conditions of each sampled landscape portion (Wimberly and Spies 2001). Main results indicated that the different influence of fire and its co-variation with topography on landscape patterns over the entire area was explained by regional conditions (i.e., topography, land cover patterns and fire history). However, results must be taken with caution because they cannot be extrapolated to other landscapes due to the inherent characteristics of this study area.

Acknowledgments Funding was provided by the EC (contract EV96-0320, project LUCIFER). I thank fruitful discussions with, and help of, Jose Manuel Moreno, Ignacio Rieiro, David Angeler, Pua Bar (Kutiel), Tal Svoray and Marie-Josee Fortin.

\section{References}

Acevedo MF, Urban DL, Ablan M (1995) Transition and gap models of forest dynamics. Ecol Appl 5:1040-1055

Agee JK (1993) Fire ecology of Pacific northwest forests. Island Press, Washington, D.C

Alexander JD, Seavy NE, Ralph CJ, Hogoboom B (2006) Vegetation and topographical correlates of fire severity from two fires in the Klamath-Siskiyou region of Oregon and California. Int J Wildland Fire 15:237-245

Allen CR, Gunderson L, Johnson AR (2005) The use of discontinuities and functional groups to assess relative reliance in complex systems. Ecosystems 8:958-966

Anderson MJ, Gribble NA (1998) Partitioning the variation among spatial, temporal and environmental components in a multivariate data set. Aust J Ecol 23:158-167

Baker WL (1989) Effect of scale and spatial heterogeneity on fire-interval distributions. Can J For Res-Revue Canadienne De Recherche Forestiere 19:700-706

Bocard D, Legendre P, Drapeau P (1992) Partialling out the spatial component of ecological variation. Ecology 73:1045-1055

Broncano MJ, Retana J (2004) Topography and forest composition affecting the variability in fire severity and postfire regeneration occurring after a large fire in the Mediterranean basin. Int J Wildland Fire 13:209-216

Bucini G, Lambin EF (2002) Fire impacts on vegetation in Central Africa, a remote-sensing-based statistical analysis. Appl Geogr 22:27-48
Carmel Y, Kadmon R, Nirel R (2001) Spatiotemporal predictive models of Mediterranean vegetation dynamics. Ecol Appl 11:268-280

CurveExpert 1.37 (2001) A comprehensive curve fitting system for Windows. Daniel Hyams, Starkville

Cushman SA, McGarigal K (2002) Hierarchical, multi-scale decomposition of species-environment relationships. Landsc Ecol 17:637-646

Cushman SA, Wallin DO (2002) Separating the effects of environmental, spatial and disturbance factors on forest community structure in the Russian far East. For Ecol Manag 168:201-215

Díaz-Delgado R, Lloret F, Pons X, Terradas J (2002) Satellite evidence of decreasing resilience in Mediterranean plant communities after recurrent fires. Ecology 83:2293-2303

Eastman JR (1999) IDRISI 3.2. Software. Clark Labs. Clark University. Worcester

ENVI (1999) The environment for visualizing images software. Research Systems, Inc., Lafayette

ESRI (1999) ArcView GIS 3.2. Software. Environmental Systems Research Institute Inc., California

Fortin MJ, Boots B, Csillag F, Remmel TK (2003) On the role of spatial stochastic models in understanding landscape indices in ecology. Oikos 102:203-212

García-Haro FJ, Gilabert MA, Meliá J (2001) Monitoring fireaffected areas using TM data. Int J Remote Sens 22:533-549

Genton MG, Butry DT, Gumpertz ML, Prestemon JP (2006) Spatio-temporal analysis of wildfire ignitions in the $\mathrm{St}$ Johns River water management district, Florida. Int J Wildland Fire 15:87-97

Güss S (2000) Cyclo-stationary maximum cross-covariance analysis for exogenously forced environmental systems. Environ Ecol Stat 7:385-404

Lentile LB, Smith FW, Shepperd WD (2006) Influence of topography and forest structure on patterns of mixed severity fire in ponderosa pine forests of the South Dakota Black Hills, USA. Int J Wildland Fire 15:557-566

Levin SA (1992) The problem of pattern and scale in ecology. Ecology 73:1943-1967

McGarigal K, Marks BJ (1995) FRAGSTATS. Spatial pattern analysis program for quantifying landscape structure. USDA For Serv Gen Tech Rep PNW-GTR-351

Mermoz M, Kitzberger T, Veblen TT (2005) Landscape influences on occurrence and spread of wildfires in Patagonian forests and shrublands. Ecology 86:2705-2715

Moloney KA, Levin SA (1996) The effect of disturbance arquitecture on landscape-level population dynamics. Ecology 77:375-394

Moreira F, Rego FC, Ferreira PC (2001) Temporal (19581995) pattern of change in a cultural landscape of northwestern Portugal: implication for fire occurrence. Landsc Ecol 16: 557-567

Moreno JM, Vázquez A, Vélez R (1998) Recent history of forest fires in Spain. In: Moreno JM (ed) Large forest fires. Backhuys Publishers, Leiden, pp 1-27

Moritz MA (2003) Spatiotemporal analysis of controls on shrubland fire regimes, age dependency and fire hazard. Ecology 84:351-361

Mouillot F, Ratte JP, Joffre R et al (2003) Some determinants of the spatio-temporal fire cycle in a Mediterranean landscape (Corsica, France). Landsc Ecol 18:665-674 
Ohmann JL, Spies TA (1998) Regional gradient analysis and spatial pattern of woody plant communities of Oregon forests. Ecol Monogr 68:151-182

Parisien MA, Peters VS, Wang YH et al (2006) Spatial patterns of forest fires in Canada, 1980-1999. Int J Wildland Fire 15:361-374

Pérez B, Moreno JM (1998) Fire-type in forestry management effects on the early postfire vegetation dynamics of a Pinus pinaster woodland. Plant Ecol 134:27-41

Pérez B, Cruz A, Fernández-González F, Moreno JM (2003) Effects of recent land-use history on the postfire vegetation of uplands in Central Spain. For Ecol Manag 182:273-283

Peroni P, Ferri F Avena GC (2000) Temporal and spatial changes in mountainous area of Central Italy. J Veg Sci 11:505-514

Perry DA (1995) Self-organizing systems across scales. TREE 10:241-244

Perry GLW, Sparrow AD, Owens IF (1999) A GIS-supported model for the simulation of the spatial structure of wildland fire, Cass Basin, New Zealand. J Appl Ecol 36: $502-518$

Peterson DG (2002) Contagious disturbance, ecological memory, and the emergence of landscape pattern. Ecosystems 5:329-338

Pickett STA, Cadenasso ML, Grove JM (2005) Biocomplexity in coupled natural-human systems: a multidimensional framework. Ecosystems 8:225-232

Podur J, Martell DL, Csillag F (2003) Spatial patterns of lightning-caused forest fires in Ontario, 1976-1998. Ecol Model 164:1-20

Pontius RG Jr (2000) Quantification error versus location error in comparison of categorical maps. Photogramm Eng Remote Sens 66:1011-1016

Pontius RG Jr, Millones M (2008) Problems and solutions for kappa-based indices of agreement. In Conference proceedings of studying, modeling and sense making of planet earth. Mytilene, Greece, $8 \mathrm{pp}$

Riano D, Moreno Ruiz JA, Isidoros D, Ustin SL (2007) Global spatial patterns and temporal trends of burned area between 1981 and 2000 using NOAA-NASA pathfinder. Glob Chang Biol 13:40-50

Rivas-Martínez S (1987) Mapa de las Series de Vegetación de España 1. 400.000. Publicaciones del Ministerio de Agricultura, Pesca y Alimentación. Instituto Nacional para la Conservación de la Naturaleza, Madrid

Rollins MG, Morgan P, Swetnam T (2002) Landscape-scale controls over 20th century fire occurrence in two large Rocky Mountain (USA) wilderness areas. Landsc Ecol 17:539-557

Romero-Calcerrada R, Perry GLW (2004) The role of land abandonment in landscape dynamics in the SPA Encinares del rio Alberche y Cofio, Central Spain, 1984-1999. Landsc Urban Plan 166:217-232

Salvador R, Lloret F, Pons X, Piñol J (2005) Does fire occurrence modify the probability of being burned again? A null hypothesis test from Mediterranean ecosystems in NE Spain. Ecol Model 188:461-469

Schroeder D, Perera AH (2002) A comparison of large-scale spatial vegetation pattern following clearcuts and fires in Ontario's boreal forests. For Ecol Manag 159:217-230

Swanson FJ Kratz TK, Caine N, Woodmansee RG (1998) Landform effects on ecosystem patterns and processes. Bioscience 38:92-98

terBraak CJF, Šmilauer P (1998) CANOCO reference manual and user's guide to CANOCO for Windows, Software for canonical community ordination (version 4.5). Microcomputer Power, Ithaca

Trabaud L, Galtiè JF (1996) Effects of fire frequency on plant communities and landscape pattern in the Massif des Aspres (southern France). Landsc Ecol 11:215-224

Turner MG, Romme WH, Gardner RH et al (1993) A revised concept of landscape equilibrium, disturbance and stability on scaled landscapes. Landsc Ecol 8:213-227

Urban DL, ÓNeill RV, Shugart HH (1987) Landscape ecology. A hierarchical perspective can help scientist understand spatial patterns. Bioscience 37:119-127

Urban DL, Acevedo MF, Garman SL (1999) Scaling fine-scale processes to large-scale patterns using models derived from models, meta-models. In: Mladenoff DJ, Baker WL (eds) Spatial modeling of forest landscape change. Approaches and applications. Cambridge University Press. Cambridge, p 351

Vázquez A, Moreno JM (1998) Patterns of lightning, and people-caused fires in peninsular Spain. Int $\mathbf{J}$ Wildland Fire 82:103-115

Vázquez A, Moreno JM (2001) Spatial distribution of forest fires in Sierra de Gredos Central Spain. For Ecol Manag 147:55-65

Viedma O, Meliá J, Segarra D, García-Haro J (1997) Modeling rates of ecosystems recovery after fires by using Landsat TM data. Remote Sens Environ 61:383-398

Viedma O, Moreno JM, Rieiro I (2004) Factors controlling the spatio-temporal dynamics of a forested landscape affected by fire in Central Spain. In: Marchetti M (ed) Monitoring and indicators of forest biodiversity in Europe-from ideas to operationality. EFI Proc 51:506-514

Viedma O, Moreno JM, Rieiro I (2006) Interactions between land use/land cover change, forest fires and landscape structure in Sierra de Gredos (Central Spain). Environ Conserv 33:212-222

Wiens JA (1989) Spatial scaling in ecology. Funct Ecol 3: 385-397

Wimberly MC, Spies TA (2001) Influences of environment and disturbance on forest patterns in coastal Oregon watersheds. Ecology 82:1443-1459

Wu J, Shen W, Sun W, Tueller PT (2002) Empirical patterns of the effects of changing scale on landscape metrics. Landsc Ecol 17:761-782

Yang J, He HS, Shifley SR, Gustafson EJ (2007) Spatial patterns of modern period human-caused fire occurrence in the Missouri OZark Highlands. For Sci 53:1-15 